\title{
IPM-FFS INSTITUTIONALIZATION IN NEPAL: A CASE STUDY
}

Kul Prasad Tiwari M.Sc ${ }^{1}$

\begin{abstract}
FFS is a form of adult education based on the philosophy of experiential learning method aimed at building farmers' expertise and capacity of analysis, critical thinking and decision-making. The objective of this paper is to assess the institutionalization status of IPM-FFS at the local level. The study is a case study and qualitative in nature. The research was conducted in Kathmandu and Tanahun districts. Hundred farmers from ten FFS, five in each of the district, were interviewed with semi-structured questionnaire. The result showed a seventy-five percent majority of FFS-graduates not having understanding and capacity of conducting experimental learning session in their own initiative. Additionally a majority of sixty percent did not use the knowledge learnt from the FFS learning session. Nevertheless, majority of the graduates acquired a lot of awareness about harmful effects of pesticides to human health, animal and environment. Likewise, eighty percent of the IPM-FFS groups did not repeat learning activities at the local level. Their majority did not share learnt skill to the non-participant farmers for its horizontal dissemination, and have a sense of ownership that empowered them to sustain the process at local level. All exhibited that IPM-FFS approach has not been institutionalized adequately for environment friendly promotion of cultivation.
\end{abstract}

Key words: Dissemination, experiential-learning, learnt-knowledge, knowledge-use

\section{INTRODUCTION}

Farmer Field School (FFS) is a form of adult education based on the philosophy of experiential learning method, aimed at building farmers' analysis, critical thinking, decision-making capacity and expertise (Nederlof and Odonkor, 2006). It is complete crop cycle learning and the general duration of school is 14-16 weeks. FFS accommodates fieldbased groups of approximately 25 to 30 farmers, who meet every week regularly to learn together through discovery and experience based method. During the learning sessions, plots of study are divided in farmers' and scientific way/IPM way of cultivation practices. The main focus of learning is to make farmers understand Agro-ecosystem Analysis (AESA), making them understanding FFS experiential learning methodology and learning process, and strengthening their capacity to understand field problems and decision-making capacity to solve their problems by themselves at the local level. However, the long-term empowerment goal of FFS is to seek enable graduate farmers to continue to expand their knowledge generation and to help others learn and to organize activities within their communities to institutionalize the learnt practices (Simpson, 2002).

In Nepal, Integrated Pest Management (IPM) FFS as a crop protection program was adopted by Ministry of Agriculture and Cooperative (MOAC) in 1990 in order to incorporate the IPM as an integral component of agriculture program to solve the farming problems in an environmentally friendly way. Nonetheless, IPM-FFS approach was adopted in 1997 in spring rice after the outbreak of Brown Plant Hopper (BHP) of rice in Chitwan district. Nepal received financial support from the Government of Norway under the technical support of FAO Regional Community IPM (CIPM) of Asia to run IPM-FFS for the duration of 1998 and 2002. Later on in January 2004, Support to National IPM-FFS Programme (SNIPM) was launched for the next three years to expand the coverage of IPM-FFS and conducting FFS in

\footnotetext{
${ }^{1}$ Agriculture Planning Officer, Dept. of Agriculture, e-mail: tiwarikp@hotmail.com
} 
different crops (PPD, 2008). Focus of the projects was to institutionalize the IPM-FFS approach in the community level so that the FFS collective learning approach would be continued after the termination of project. In this context, the scope of this study is to assess the kinds of learning and change process IPM-FFS approach has created at local level.

\section{THEORETICAL FRAMEWORK}

Experiential Learning Theory (ELT) was used to gauge the institutionalization status of IPMFFS. The theory is a knowledge creation process through which new experiences are integrated into prior experiences and transformed into relevant, durable and retrievable knowledge suitable for use in the learners' environment (Kolb 1984; Sheckley and Keeton, 1997; Ndoye, 2003). Major focus of this theory is the generation of new knowledge and

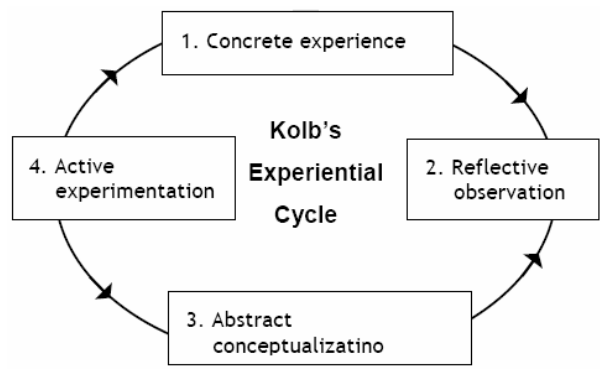

Fig.1: Experiential Learning Cycle (Kolb, 1984) application of acquired knowledge and behaviour in the real field. Additionally, the experiential learning theory is conceived as a process that contrasting to an outcome continues after completion of one cycle. The main emphasis of FFS is on collective learning and knowledge sharing among farmers that needs to be continued after the first and second round of FFS learning sessions in order to solve the farming problems constantly and to institutionalize the process in the local level.

\section{METHODOLOGY}

For this study, a case study was conducted for gaining a deep insight about the institutionalization status of IPM-FFS. For gathering the data, Tanahun and Kathmadu districts were selected purposively because in both of districts IPM-FFS project were implemented to promote and institutionalize FFS approach. From within the district, IPMFFS groups were selected randomly from the lists of DADOs. From Tanahun, 5 IPM-FFS groups were selected out of 23 and from the Kathmandu 5 IPM-FFS groups were chosen from the list of 22 IPM-FFS of DADO. This research was conducted from September 2008 to March 2009. Different research units were used to gain clear understanding of learning and change processes. The research units were the IPM-FFS groups, IPM-FFS farmer facilitators' associations, District Agriculture Development Offices (DADOs) etc. Several data collection techniques were used. The focus group discussion especially to IPM FFS groups, informal discussion with the IPM FFS participants, Semi-structured and informal interview with individual IPM FFS participants, IPM FFS facilitators. In total 100 IPM FFS participant farmers were involved in focused group discussion, 100 IPM FFS farmers were involved in informal, semi-structure and structured interview, 10 IPM FFS facilitators. Besides the primary sources of information, secondary data were also collected from the reports and different kinds of publications related to IPM FFS.

\section{RESULTS AND DISCUSSIONS}

\section{EXPERIENTIAL LEARNING SESSION}

An effective farmer participatory research needs understanding and motivation of farmers rather than commanding and need to provide balance rules with freedom for creativity and room for manoeuvre (Veldhuizen et al., 2002. The study showed that during the experiential learning session, a democratic forum was provided for active participation in the learning process. Participants were encouraged by the FFS facilitators to directly involve in experiencing the problems, reflective observation over the problems, 
conceptualizing the problems and active experimentation in the field for generating the solution.

The participant farmers said: "We used to observe the phenomenon or problems critically in groups, discuss over the events among the participants, analyse the issues in the groups and used to decide collectively for active experimentation to solve problems. For example, we used to observe insects on growing crops; we used to discuss, analyse and reflect over their behaviour to identify whether they are harmful or beneficial insects. By continuous observation and looking at their behaviours and effects on crops, we finally used to conceptualize that these insects were harmful or beneficial insects". Therefore, FFS farmers have good understanding about beneficial and harmful insects.

Table 1. FFS-farmers able to identify beneficial-harmful insects

\begin{tabular}{l|l|l|l}
\hline S.N & Category of farmers & $\begin{array}{l}\text { No of } \\
\text { farmers }\end{array}$ & $\begin{array}{l}\% \text { of } \\
\text { farmers }\end{array}$ \\
\hline 1 & $\begin{array}{l}\text { Farmers who can identify the } \\
\text { harmful and beneficial insects }\end{array}$ & 140 & 70 \\
2 & $\begin{array}{l}\text { Farmers who can not identify the } \\
\text { harmful and beneficial insects }\end{array}$ & 60 & 30 \\
\hline & Total No farmers & 200 & \\
\hline
\end{tabular}

From the study, as mentioned in table 1 , it is found that $70 \%$ of the graduate farmers can identify and have insight about the harmful and beneficial insects. Before the FFS learning session, they had perception that all insects, those are seen in the field, are harmful to the crops but after the IPM-FFF they can identify some major beneficial insects like, lady bird beetle, wasps, spider, tiger beetle, damselfly, dragonfly, etc. Furthermore, they have good knowledge about harmful insects like cabbage butterfly, diamond back moth, leaf folder, grasshopper, stems borer, rice bug, aphid etc. Additionally, this study also found that majority of the FFS graduates has acquired good knowledge and skills about preparing the botanical pesticides from the local plant materials to control the insect pests in an environmentally friendly way.

However, though FFS graduates can identify the harmful or beneficial insects and have understanding and skills of preparing bio-pesticides, majority of the participants do not have understanding about experiential learning process that is they do not have confidence and knowledge about organizing and conducting the experimental learning process by their own efforts and capacity.

Table 2. FFS graduate farmers' having understanding of experiential learning process

\begin{tabular}{|c|c|c|c|}
\hline S.N & Category of farmers & $\begin{array}{l}\text { No of } \\
\text { farmers }\end{array}$ & $\begin{array}{l}\% \text { of } \\
\text { farmers }\end{array}$ \\
\hline 1 & $\begin{array}{l}\text { Have understanding of } \\
\text { experiential learning process }\end{array}$ & 50 & 25 \\
\hline \multirow[t]{2}{*}{2} & $\begin{array}{l}\text { Do not have understanding of } \\
\text { experiential learning process }\end{array}$ & 150 & 75 \\
\hline & Total No farmers & 200 & 100 \\
\hline
\end{tabular}

As indicated in table 2, majority $(75 \%)$ of the graduate farmers said that they could not conduct the experimental learning session by their own knowledge and initiative without support of FFS facilitators. Therefore, experimental learning session has not sufficiently developed insight and the self-confidence in the FFS graduates for solving local problems by their own. The most importantly, the graduate farmers do not have clear understanding and logic behind the experimental knowledge generation process. Only the leader farmers and/or the leaders of IPM-FFS groups and literate graduates have understanding about experiential learning processes that need to be carried out in the field while conducting the experiential learning session. From the study, it is found that, most of the FFS participant farmers who were illiterate were not actively involved in the learning process. They felt inferior in the learning process and, therefore, they escape during group discussion, argumentation and presentation sessions so that they do not have clear insight about the experiential learning process. 


\section{USE OF LEARNT KNOWLEDGE}

Hammond (2002, as cited by Nederlof and Odonkor, 2006) argue that FFSs are introduced to bridge the gap between technology development on the one hand and adoption of technology on the other hand. The focus of the IPM-FFS is to make farmers to adopt and use the generate knowledge, learned skills and behaviour after the termination of learning cycle. However, it is found that a $60 \%$ majority of the graduates (table 3 ) do not use the generated knowledge, learnt behaviour, skills and practices from the FFS experimental cycle. Preparation/use of organic manure/compost, preparation/application of botanical pesticides, right time/correct amount of pesticide use, using protective materials while applying pesticides, observing the crops in field regularly and trying to identify the field problems individually or collectively, identifying the harmful/beneficial insects and using fertilizer in correct amount and time are some of the commonly learnt behaviour, skills and practices from the FFS as mentioned by the farmers. The reasons for not adopting these learnt knowledge and practices are owing to labour intensiveness and time consuming nature of these practices and learnt skills; lack of collective efforts or actions after FFS learning session; minimal logical understanding about learnt practices etc. For example, none of the interviewed graduates prepare the botanical pesticides in their home individually or collectively to control the insect pests and to save the environment from polluting from chemical pesticides. Generally, it is found that graduate farmers do not use the knowledge and practices which need more efforts to bring them into practice. In the same way, the IPM-FFS graduates do not follow the protective techniques/safety measures while spraying the pesticides in the field crops.

Table 4. What practices, learnt knowledge and skills FFS-graduates do use and do not use

\begin{tabular}{l|l}
\hline The FFS-graduates do use & The FFS-graduates do not use \\
\hline -Organic/compost manure & -Botanical pesticides \\
-A few (2-4) no. of seedlings while transplanting rice & -Protective measures while spraying pesticide \\
-Observing insects for their harmful/beneficial roles & -Observe field, insects and diseases in groups \\
-Correct doses of pesticides & -Discuss field problems in groups \\
-Appropriate dose and time of fertilizer application & -Agriculture lime \\
\end{tabular}

Even thought majority of farmers do not use generated knowledge, learnt behaviour and practices from FFS, the graduates have acquired a lot of awareness about harmful effects of chemical pesticides to human health, animal and environment. For example, before FFS training, they used to apply chemical pesticides haphazardly (over dose than required) according to majority of interviewed farmers, nowadays they use the chemical pesticides only after confirming whether the insects seen in the field are harmful or beneficial. Furthermore, as said by most of the farmers they are more aware of safety measures of chemical pesticides and therefore, the frequencies of using chemical pesticides have dwindled after the FFS sessions. Likewise, the FFS participants mentioned that they have been using fertilizers in inappropriate time. After FFS they learnt that only applying fertilizer is not beneficial and do not increase yield of crops. What they learnt is right time of applying fertilizer that is more important to boost up the yields of the crops.

\section{CONTINUITY OF KNOWLEDGE GENERATION PROCESS}

Continuity of FFS learning approach at the local level can be viewed from two aspects. One is follow up learning process at the already established FFS groups and another is up scaling of FFS learning approach in the new areas. Both follow up and up scaling of FFS learning are important for the sustainability of FFS approach. Pimbert (2002, cited by CIP-Upward, 
2003) state that after completion of one cycle of FFS training, if follow up action does not persist, the learners and facilitators will continuously lose their knowledge and skills and learning process cannot sustain at the local level.

Table 5. Continuity of knowledge generation process by FFS groups

\begin{tabular}{c|l|c|c}
\hline S.N. & Category of groups & $\begin{array}{l}\text { No of } \\
\text { farmers }\end{array}$ & $\begin{array}{c}\% \text { of } \\
\text { groups }\end{array}$ \\
\hline 1 & $\begin{array}{l}\text { FFS groups have given } \\
\text { continuity to experiential } \\
\text { knowledge generation process }\end{array}$ & 2 & 20 \\
2 & $\begin{array}{l}\text { FFS groups do not have given } \\
\text { continuity to experiential } \\
\text { knowledge generation process }\end{array}$ & 8 & 80 \\
\hline & Total No of groups & 10 & \\
\hline
\end{tabular}

As revealed in table 5 , it is discovered that after the completions of IPM-FFS training, $80 \%$ of the IPM-FFS groups do not repeat collective learning activities at the local level. Only $20 \%$ (2 out 10) IPM-FFS groups' have given continuity to the knowledge generation process by their own effort at the community level after the completion of first and second round of FFS. The ex-participants of Mulpani IPM-FFS groups have established study plots after the collective FFS learning session. Especially these plots are for testing new tomato crop varieties to find out whether these varieties are resistance to blight or not.

Thus, it can be said that the graduate farmers do not have ownership feeling over the FFS experiential learning cycle to be repeated at the local level. The farmers are not empowered and motivated sufficiently to repeat the process after FFS learning cycle to sustain the process at the community level.

Even if majority of FFS groups do not continuously involve in the experiential learning activities; joint learning habits have been developed in them. When these farmers notice some insects or diseased plant or other problems on crops, they bring the plant parts in the group meeting and try to find out the problems and/or generate the solutions by group discussion, analysis and collective conclusion. Even group members gather in the field to observe the problems in case of need. This process has helped to promote joint learning and problem solving habits of IPM-FFS graduates.

From this study, it is discovered that IPM-FFS groups are not taking initiative to give continuity to the experiential learning process. Most of the IPM-FFS groups are expecting regular support from the DADOs and other organizations to organize and to give continuity to the IPM-FFS knowledge generation process rather than conducting the process by their own capacity and using their own resources and knowledge.

IPM-FFS (farmer) facilitators who, are supposed to provide support to FFS graduates and FFS groups after FFS training for promotion of learning at the local level, are not supportive for giving continuity of collective learning activities. The IPM-FFS facilitators are not active and effective for promoting environmentally friendly IPM-FFS learning activities at their neighbourhood after completion of either first or second learning cycle. The reason is that they demand incentives for conducting the learning activities rather than providing voluntary services at the local level. So, there is question over the persistence of IPM-FFS activities after the termination of project.

\section{DISSEMINATION OF LEARNT KNOWLEDGE}

One of the functions of FFS approach is to promote farmer-to-farmer diffusion of knowledge (Berg, 2003; Nederlof and Odonkor, 2006). FFS approach achieves very limited coverage unless there is an organized effort for the dissemination of knowledge. An effective diffusion mechanism enhances neighbour-to-neighbour learning and sharing (Pimbert, 2002 cited by CIP-UPWARD, 2003). Farmer to farmer diffusion of knowledge, practices and information is important aspect of FFS. 
From this study, it is found that field day/FFS closing day is an important forum for disseminating the knowledge and technologies generated from FFS. On the occasion of field day, farmers, teachers, students, agriculture technicians, political local leaders are invited to observe the closing ceremony and on that day they can observe the generated knowledge and technologies from IPM-FFS. The invitees can see the plots of IPM and farmer's traditional method of cultivation and experimental trial. The observers can see and compare the products produced by IPM-FFS methods and traditional farmer method. The invitees can see the drawings and real specimens of beneficial and harmful insects, learned and collected during FFS learning.

Nonetheless, from this study what is learnt is that in the closing ceremony many activities are performed in a single day, participants and facilitators do everything in hurry up so it is not easy to the audiences, especially of non-participant farmers, who are supposed to learn important lessons, information, ideas and knowledge delivered in the field day and also outputs of FFS. Limited time is available to FFS farmers explaining what they learnt during the FFS sessions to the non-participant farmers. Priority is given to the big bosses and invitees (bureaucrats, and political leaders) rather than providing more space for disseminating generated knowledge to the non-participant farmers.

In addition to that none of the IPM-FFS groups has any mechanism and commitment to disseminate the generated knowledge to the non-participant farmers. Even the FFS groups do not encourage their members for sharing the learnt knowledge to other non-participant farmers for wider dissemination of generated knowledge from the FFS.

Table 6. Sharing and dissemination of learnt knowledge and skills by FFS-participants to non-participants

\begin{tabular}{c|l|c|c}
\hline S.N & Category of farmers & $\begin{array}{l}\text { No of } \\
\text { farmers }\end{array}$ & $\begin{array}{c}\% \text { of } \\
\text { farmers }\end{array}$ \\
\hline 1 & $\begin{array}{l}\text { Farmers who share and } \\
\text { disseminate the learnt knowledge } \\
\text { and skills }\end{array}$ & 40 & 20 \\
2 & $\begin{array}{l}\text { Farmers who do not share and } \\
\text { disseminate the learnt knowledge } \\
\text { and skills }\end{array}$ & 160 & 80 \\
\hline & Total No farmers & 200 & 100 \\
\hline
\end{tabular}

In case of individual sharing of knowledge, as stated in table 6 , only $20 \%$ of FFS graduates do share the learnt knowledge to the non-participant farmers and in most of cases they shares the learnt knowledge only to the relatives, friends and neighbours. Furthermore, the FFS participants mostly share theoretical knowledge

like bad effects of pesticides to human health and environment and ideas and knowledge about beneficial and harmful insects rather than teaching skill oriented knowledge and practices like preparation of botanical pesticides, conducting experiment in the field, regular field observation, showing the harmful insects and their symptoms of damages.

Also IPM-FFS facilitators neither do involve in the spreading of the knowledge generated from FFS nor do they encourage the FFS graduates for sharing the learnt knowledge and generated innovation to the non-participant farmers. However, the facilitators are considered the village level motivators or promoters for sustaining the FFS learning and sharing activities after completion of experimental cycles.

\section{CONCLUSIONS}

FFS is a medium for collective learning by the participants by themselves. Self-learning and open democratic discussion, decision-making and experimentation session is crucial to understand learning process. During the FFS learning session, self-learning and self-decision making atmosphere is provided to the farmers. However, majority of farmers do not actively involve in self-experiencing, theorizing the problems and ultimately active experimentation for the solution. Mostly, leaders of sub-groups and literate farmers take lead in the experimental learning sessions. Consequently, majority $(75 \%)$ of the graduate 
farmers do not have understanding and capacity to conduct the experimental learning session by their own knowledge, efforts and initiative.

In the majority $(60 \%)$ of FFS participants do not use the generated technologies from the FFS learning sessions and the reason is because of labour-intensiveness and time consuming nature of technology for using and absence of collective efforts for making use of the learnt knowledge. But abundant awareness have developed in the graduate farmers concerning to harmfulness of chemical pesticides not only to human health but to surrounding environment. In case of persistence of experimental learning activities, only $20 \%$ of FFS groups have given continuity to learning process by their own efforts. This reveals that majority of FFS graduates do not have ownership feelings over FFS, a collective learning activities.

Concerning to horizontal dissemination of generated knowledge, there are not strong mechanisms for spreading the knowledge produced from FFS. Field Day is little bit effective mechanism but in Field Day more priority is given to the speeches of guests (bureaucrat and political persons) rather than promoting farmer to farmer interaction and sharing. After FFS learning sessions, only around $20 \%$ of farmers share knowledge to the non-participants.

Finally, FFS does not have sufficiently capacitated the graduate farmers to understand the process and run the FFS by their local resources and to sustain the process. The FFS farmers are not motivated to use the acquired knowledge and skills from the discovering based learning sessions. The FFS sessions are unable to change farmer's traditional practices and behaviours. Moreover, the school graduates do not have tendency to share the learnt knowledge to other non-participants of the villages and even of neighbourhoods to spread the innovation horizontally. Nevertheless, sufficient awareness can be seen in the FFS graduates concerning to harmfulness of chemical pesticides to human, animal and environment. Graduate farmers' cognizance regarding beneficial and harmful insects is also matter of appreciable that has diminished the haphazard use of pesticides and bolsters to save the environment to some extent.

\section{REFERENCES}

CIP-UPWARD, 2003. Farmer Field School: From IPM to Platform of learning and empowerment. International Potato Centre -Users' Perspectives with Agricultural Research and Development, Los Bonos, Philippines. Rockefeller foundation.

Kolb, D.A., 1984. Experiential Learning: Experience as the source of Learning and Development. Prentice-Hall, Inc., New Jorsey.

Nederlof, E. S. and E. N. Odonkor, 2006. Lessons from an Experiential Learning Process: The Case of Cowpea Farmer Field Schools in Ghana, Journal of Agricultural Education and Extension, 12(4), pp. 249-271.

Ndoye, A., 2003. Experiential learning, self-beliefs and adult performance. In: Senegal Lifelong Education, 22 (4), pp.353-366.

PPD, 2008. Annual Progress Report. Plant Protection Directorate, Department of Agriculture (DOA), Harihar Bhawan, Nepal.

Simpson, B. M., 2002. Farmer field schools and the future of agricultural extension in Africa Faculty, Department of Resource Development, Michigan State University and Consultant in Agriculture and Rural Development, Kevin Court Zionsville, USA.

Van Veldhuizen, L., A., Waters-Bayer, S. Killough, M. Espineli and J. Gonsalves, 2002. Institutionalizing Farmers Participatory Research. In: C. Leeuwis and R. Pyburn (eds.), Wheelbarrow Full of Frogs. Social Learning for Natural Resource Management. Koninklijke van Gorcum, Assen, The Netherlands, pp. 275-390. 